\title{
Oxidation Reactions of Dibenzothiophene Subjected to Negative Chemical Ionization with Oxygen*
}

\author{
Georg Drabner and Herbert Budzikiewicz \\ Institut für Organische Chemie der Universität, Köln, Germany
}

Dibenzothiophene (1) suffers surface-catalyzed oxidation under $\mathrm{Cl}\left(\mathrm{O}_{2}\right)$ conditions. While in the positive mode $\mathrm{M}^{+}$is the only major ion and those of the oxidation products are of minor importance in the negative mode, essentially only ions stemming from oxidized species can be seen, the sulfone ion $\left[\mathrm{M}+\mathrm{O}_{2}\right]^{\cdots}$ being the most important one. The ion $m / z 184$ previously attributed to $\mathrm{M}^{-}$is actually the anion of 2-sulfobenzoic acid cyclic anhydride. Structures for the various oxidation products are proposed and the mechanisms leading to their formation are discussed. (J Am Soc Mass Spectrom 1993, 4, 949-954)

$\mathrm{I}$

$n$ an early communication on negative chemical ionization (NCI) mass spectrometry, Hunt et al. [2] Leported that isobaric aromatic hydrocarbons and sulfides can readily be distinguished by their $\mathrm{NCI}\left(\mathrm{O}_{2}\right)$ mass spectra: The former give $\mathrm{M}^{-}$and $[M+15]^{-}$ (phenolate) ions, the latter $\mathrm{M}^{-}$and $[\mathrm{M}+32]^{-}$(presumably sulfone [3]) ions. The importance of this observation for the analysis of high boiling petroleum fractions was pointed out $[2,3]$, but in each case only dibenzothiophene (1) was mentioned as an example. However, for an actual analysis, rather than using $\mathrm{NCI}\left(\mathrm{O}_{2}\right)$, collision activation spectra of the $[\mathrm{M}+\mathrm{H}]^{+}$ ions of the parent compounds and of the $[\mathrm{M}+\mathrm{NO}]^{+}$ ions of the sulfones obtained by preceding oxidation were used [4].

For the $\mathrm{NCI}\left(\mathrm{O}_{2}\right)$ mass spectra of 1 obtained by I Iunt et al. with $90 \% \mathrm{O}_{2}$ and $10 \% \mathrm{H}_{2}$, it was reported [2] $m / z 216\left(\left[\mathrm{M}+\mathrm{O}_{2}\right]^{-}\right), 184\left(\mathrm{M}^{-}\right)$and $32\left(\mathrm{O}_{2}^{-}\right)$, but also [5] $m / z 216,183\left([\mathrm{M}-\mathrm{H}]^{-}\right), 96\left(\mathrm{SO}_{4}^{-}\right)$and 64 $\left(\mathrm{SO}_{2}^{-}\right)$. These spectra differ grossly from those where $\mathrm{O}_{2}$ only plays a partial role as a contaminant: $v$. Ardenne et al. [6], using a low pressure discharge in Ar, observed $m / z 199\left([\mathrm{M}+\mathrm{O}-\mathrm{H}]^{-}\right), 183([\mathrm{M}-$ $\left.\mathrm{H}^{-}\right), 137,105,81$ ( $\mathrm{HSO}_{3}^{-}$, base peak). Under similar conditions Albers and Knof [7] obtained $m / z 199$ as the base peak. Tokarev et al. [8] reported that under $\operatorname{NCI}\left(i-\mathrm{C}_{4} \mathrm{H}_{10}\right)$ conditions 1 gives $m / z 183\left([\mathrm{M}-\mathrm{H}]^{-}\right)$ as the major peak and small amounts of $m / z 33$ $\left(\mathrm{SH}^{-}\right) .[\mathrm{M}+\mathrm{O}-\mathrm{H}]^{-}$ions are frequently encountered as side-products of aromatic compounds when nonreactive reagent gases are used $[9,10]$. 'I'heir genesis is explained by ion-molecule reactions of sample molecules with $\mathrm{O}^{-}$or $\mathrm{OH}^{-}$derived from trace

\footnotetext{
*Part XXVII: Studies in chemical ionization. For part XXVI, see reference 1.

Address reprint requests to l'rof. Dr. Budzikiewicz, Institut für Organische Chemie der Universität zu Köln, Greinstr. 4, D-50939
} Köln, Germany. amounts of $\mathrm{O}_{2}$ and $\mathrm{H}_{2} \mathrm{O}$ present in the ion source [9, 10]. $[\mathrm{M}-\mathrm{H}]^{-}$ions may either be formed by dissociative electron capture or by deprotonation by basic species such as $\mathrm{O}^{-}$or $\mathrm{OH}^{-}[9,10]$. Besides $\mathrm{O}^{-}$ (which in the experiments of Hunt et al. [2] was removed by the addition of $\mathrm{H}_{2}$ ), the basic reagent ions $\mathrm{O}_{2}^{-}$and $\mathrm{OH}^{-}$[11] are present in the $\mathrm{O}_{2}$ plasma and it is, therefore, rather surprising that $\mathrm{M}^{-} \cdot(\mathrm{m} / z$ 184) should be observed [2] in the $\mathrm{NCI}\left(\mathrm{O}_{2}\right)$ mass spectrum of 1 , whereas $[\mathrm{M}-\mathrm{H}]^{-}$and not $\mathrm{M}^{-}$is formed [8] even when electron capture promoting hydrocarbon reagent gases such as $i-\mathrm{C}_{4} \mathrm{H}_{10}$ are used.

To find an explanation for the discrepancies in the NCI mass spectra of $\mathbf{1}$ and to examine whether [M + $\left.\mathrm{O}_{2}\right]^{-\cdot}$ (sulfone) ions are typical for thiophenes in general, we studied the NCI mass spectra of 1 and of some related compounds in detail.

\section{Experimental}

\section{Instrumentation}

The $\mathrm{CI}\left(\mathrm{O}_{2}\right)$ mass spectra were measured with a Varian-MAT (Bremen, Germany) 212 instrument equipped with a modified electron ionization/chemical ionization (EI/CI) source and a glow discharge probe [12] (discharge current $0.025-0.080 \mathrm{~mA}$, discharge voltage $0.8-1.1 \mathrm{kV}$, source temperature $80-130^{\circ} \mathrm{C}$, pressure inside the source $40-60 \mathrm{~Pa})$. $\mathrm{CI}\left(\mathrm{CH}_{4}\right)$ and $\mathrm{CI}\left(\mathrm{N}_{2} \mathrm{O}\right)$ spectra were obtained using a rhenium band cathode [emission current $0.5 \mathrm{~mA}$, electron energy $130 \mathrm{eV}$ $\left(\mathrm{CI}\left(\mathrm{CH}_{4}\right)\right)$ and $60 \mathrm{eV}\left(\mathrm{CI}\left(\mathrm{N}_{2} \mathrm{O}\right)\right)$, pressure inside the source $40-60 \mathrm{~Pa}$, temperature $100^{-}-140^{\circ} \mathrm{C}$. Pressures inside the ion source were measured with a measuring probe equipped with a thermocouple vacuum gauge. NCI spectra were recorded without the conversion dynode. Samples were introduced with a modified [13] direct insertion probe (IGT, Much, Germany). For gas 
chromatography/EI (GC/EI) measurements (electron energy $70 \mathrm{eV}$, emission current $1 \mathrm{~mA}$, pressure $2 \cdot 10^{-3}$ $\mathrm{Pa}$, temperature $140^{\circ} \mathrm{C}$ ), samples were introduced via a Varian 3700 gas chromatograph (SE-54 fused-silica column).

\section{Materials}

The reagent gases used came from Messer-Griesheim (Düsseldorf, Germany) $\left[\mathrm{O}_{2}\right.$ (purity $\geq 99.998 \%$ ), $\mathrm{CH}_{4}$ $\left.(\geq 99.995 \%), \mathrm{N}_{2} \mathrm{O}(\geq 99.0 \%)\right]$ and Chemotrade (Leip$\mathrm{zig}$, Germany) $\left[{ }^{18} \mathrm{O}_{2}\right.$ (isotopic purity $99.5 \%{ }^{18} \mathrm{O}$ )].

Dibenzothiophene, dibenzothiophene 5,5-dioxide, dibenzofuran, $9 \mathrm{H}$-carbazole, $3 \mathrm{H}$-2,1-benzoxathiol-3-one 1,1-dioxide (2-sulfobenzoic acid cyclic anhydride), and the starting materials for syntheses came from Aldrich (Steinheim, Germany), Fluka (Buchs, Switzerland), and Merck-Schuchardt (Hohenbrunn, Germany), dibenzothiophene- $d_{8}$ from MSD Isotopes (Montreal, Canada), and were used without further purification. 1- [14, 15], 2- [16], 3- [14, 15], 4-methyl- [16], 1,3- [14, 15], 2,8-dimethyldibenzothiophene $[17,18]$, and naphtho[ $[2,3-b]$ thiophene $[19,20]$ were prepared by literature procedures. Dibenz $[c, e][1,2]$ oxathiin 6 -oxide was synthesized [21] from biphenyl-2-ol and 2-methyldibenz $[c, e][1,2]$ oxathiin 6-oxide in an analogous way from 5-methylbiphenyl-2-ol [22]. Dibenzothiophene 5oxide when synthesized according to ref 23 contained some dibenzothiophene 5,5-dioxide and was purified by column chromatography (silica gel, eluent $\mathrm{CH}_{2} \mathrm{Cl}_{2}$ ). 2-Sulfobenzoic acid was converted into its dimethylester by reaction with diazomethane [24].

Oxidation of dibenzothiophene. Fifty milligrams $(0.27$ mmol) of dibenzothiophene were stirred under reflux for $4 \mathrm{~h}$ with a solution of $260 \mathrm{mg}$ ( $1.65 \mathrm{mmol})$ potassium manganate(VII) in $15 \mathrm{ml} \mathrm{H}_{2} \mathrm{O}$. After cooling to room temperature the excess of $\mathrm{KMnO}_{4}$ was destroyed by addition of an aqueous solution of manganese(II) sulfate. The reaction mixture was acidified $(\mathrm{pH} 2)$, freed from $\mathrm{MnO}_{2}$ by filtration, and evaporated to dryness. The residue was taken up in $30 \mathrm{ml}$ acetone, filtered, and again evaporated to dryness, taken up in $30 \mathrm{ml}$ methanol and methylated with $200 \mathrm{mg}(4.7$ mmol) diazomethane [24].

All compounds were characterized by GC/EI and by their ${ }^{1} \mathrm{H}$ - and ${ }^{13} \mathrm{C}$-NMR spectra.

\section{Results and Discussion}

Our $\mathrm{NCI}\left(\mathrm{CH}_{4}\right)$ spectrum of 1 shows $\mathrm{m} / \mathrm{z} 183$ ([M $\mathrm{H}^{-}$) as the only ion, thus confirming the results of Tokarev et al. [8]. $\mathrm{N}_{2} \mathrm{O}$, which yields $\mathrm{O}^{-}$, produces mainly $m / z 64$ (rel. int. 100\%) and $m / z 199$ ([M + O $\left.-\mathrm{H}]^{-}, 90 \%\right)$ and small amounts of $m / z 182([\mathrm{M}-$ $\left.2 \mathrm{H}]^{-}, 13 \%\right), 183\left(\left[\mathrm{M}-\mathrm{H}^{-}, 4 \%\right), 213([\mathrm{M}+\mathrm{NO}-\right.$ $\left.\mathrm{H}]^{-} ; 6 \%\right)$, and $227\left(\left[\mathrm{M}+\mathrm{N}_{2} \mathrm{O}-\mathrm{H}\right]^{-}, 3 \%\right)$. Analogous species, except $m / z$ 64, have also been observed with anthracene $[10]$ and several other aromatic hydrocarbons [25]. The low abundance of the $m / z 199$ (phe- nolate) ion in the $\mathrm{NCI}\left(\mathrm{O}_{2}\right)$ spectrum (Figure 2: see discussion below) shows that the reaction of 1 with $\mathrm{O}^{-\cdot}$ is a relatively slow process as compared to the oxidation of 1 (see below) and subsequent electron attachment to the oxidation products.

The $\mathrm{O}_{2}$ plasma has been described in the literature as consisting of $\mathrm{O}^{-}$and $\mathrm{O}_{2}^{-}[26,27]$, and occasionally $\mathrm{O}_{3}^{-}$is mentioned [28]. This description is rather euphemistic as reaction products with $\mathrm{H}_{2} \mathrm{O}\left(\rightarrow \mathrm{OH}^{-}\right)$ and $\mathrm{N}_{2}\left(\rightarrow \mathrm{NO}_{2}^{-}, \mathrm{N}_{2} \mathrm{O}_{2}^{-}\right)$as well as desorbed halogen ions $\left(\mathrm{F}^{-}, \mathrm{Cl}^{-}\right)[29]$ are observed in praxi with appreciable abundance as contaminants. The composition of the $\mathrm{O}_{2}$ plasma used in our experiments obtained with a glow discharge source [12] can be seen in Figure 1.

Figure 2 shows the $\mathrm{NCl}\left(\mathrm{O}_{2}\right)$ spectrum of 1 and Figure 3 that of its perdeuterated analog 2. NCI spectra were also obtained with ${ }^{18} \mathrm{O}_{2}$. The elemental compositions of the ions mentioned below are in agreement with the number of ${ }^{18} \mathrm{O}$ and ${ }^{2} \mathrm{H}$ atoms incorporated (see Table 1). In the lower mass region the oxidation products of sulfur $\left[\mathrm{m} / \mathrm{z} 64\left(\mathrm{SO}_{2}^{-}\right), 80\left(\mathrm{SO}_{3}^{-}\right)\right.$, and $96\left(\mathrm{SO}_{4}^{-}\right)$, cf. [5]], as well as ions stemming from a complete oxidative degradation of 1 (e.g., $m / z \quad 73, \mathrm{CHO}-\mathrm{COO}^{-} ; m / z \quad 112 / 113$, (H)OOC $-\mathrm{C} \equiv \mathrm{C}-\mathrm{COO}$ ), can be seen. The ions which in the spectra of other aromatic compounds have been ascribed to ion-molecule reactions in the gas phase $[9,10]$, viz. $[\mathrm{M}-\mathrm{H}]^{-}(m / z 183)$ and $[\mathrm{M}+$ $\mathrm{O}-\mathrm{H}]^{-}(m / z 199)$, are of minor importance. The [M $\left.+\mathrm{O}_{2}\right]^{-\cdot}$ ion $(m / z 216)$ first observed by Hunt et al. [2] clearly dominates the upper mass range, but it is imbedded into a series of $\left[\mathrm{M}+\mathrm{O}_{\mathrm{n}}\right]^{-}$ions $(\mathrm{n}=1 \mathrm{up}$ to $\mathrm{n}=4$ ) and is accompanied by ions of the composition $\left[\mathrm{M}+\mathrm{O}_{\mathrm{n}}-2 \mathrm{H}\right]^{-}(\mathrm{n}=2 \ldots 4)$ with varying abundance. Regarding the ions $m / z 262,264$ and 280, see below.

The ion $\left[\mathrm{M}+\mathrm{O}_{2}\right]^{-\cdot}$ could either be a cluster ion between $M$ and $O_{2} \cdot[9,10]$ (in which case it would belong to the ion-molecule-reaction products; the alternative $\mathrm{M}^{-}+\mathrm{O}_{2}$ [30] can be excluded for reasons given below), or an oxidation product of 1 such as the corresponding sulfone 3 [3] or its rearrangement product, the sulfinate 4 . In this case a surface-catalyzed reaction has to be taken into account. It will be shown that the last mentioned possibility is the most likely one and that the formation of the other prominent ions

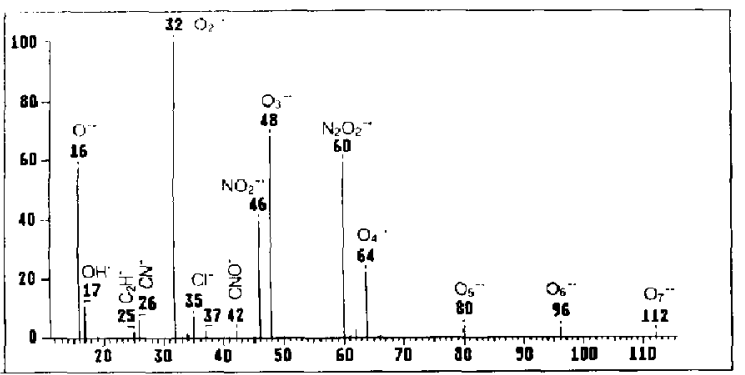

Figure 1. Negative ion mass spectrum of the $\mathrm{O}_{2}$-plasma. 


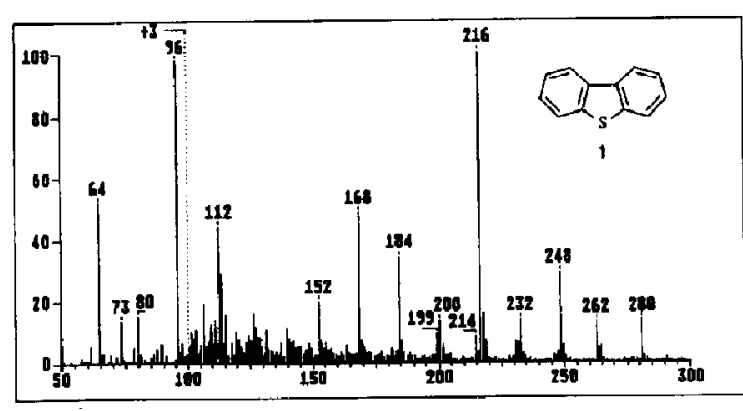

Figure 2. $\mathrm{NCl}\left(\mathrm{O}_{2}\right)$ mass spectrum of dibenzothiophene $1(\mathrm{M}=$ 184).

in the upper mass range of Figure 2 can be explained in this way also.

1 forms in the positive $\mathrm{CI}\left(\mathrm{O}_{2}\right)$ spectrum $\mathrm{M}^{+\cdot}(\mathrm{m} / \mathrm{z}$ 184 , rel. int. $100 \%$ ) and in small amounts ions of the oxidation products as $m / z 216(2 \%), 200\left([\mathrm{M}+\mathrm{O}]^{+}\right.$; $<1 \%), 232\left([\mathrm{M}+3 \mathrm{O}]^{+} ; 1 \%\right)$, and, of importance in this discussion, $168\left([\mathrm{M}+2 \mathrm{O}-\mathrm{SO}]^{+} ; 3 \%\right)$ (all peaks are shifted accordingly by $8 \mathrm{u}$ in the spectrum of 2 ). Hence, oxidation of the sulfur atom to give 3 must have occurred followed by ionization to $3^{+\cdot}$ and subsecuent rearrangement to $4^{+}$which then eliminates SO. The ion $m / z 168$ occurs also in the EI spectrum of $3[31,32]$ and rearrangements as $3^{+\cdot} \rightarrow 4^{+-}$are typical for sulfones in general [33]. 3 can also be transformed thermally into 4 [32]. The formation of $\left[\mathrm{M}+\mathrm{O}_{2}\right]$ ions both in the positive and in the negative mode makes a surface reaction very likely. (Note that when the sample is introduced via a gas chromatograph the ion chromatogram of $m / z 216$ obtained from 1 by $\mathrm{NCI}\left(\mathrm{O}_{2}\right)$ shows the same tailing which was observed for the $[\mathrm{M}+\mathrm{O}-2 \mathrm{H}]^{-}$peak obtained from fluorene by $\mathrm{NCI}\left(\mathrm{O}_{2} / \mathrm{N}_{2}\right)$ and which was explained by adsorption

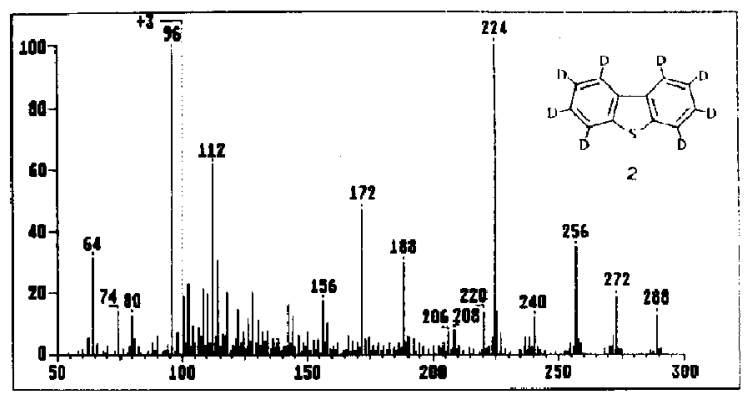

Figure 3. $\mathrm{NCI}\left(\mathrm{O}_{2}\right)$ mass spectrum of dibenzothiophene-d $\mathrm{d}_{8} 2$ $(\mathbf{M}=192)$.

of $\mathrm{M}$ on the metal surface of the ion source and retarded desorption and subsequent ionization of the oxidation product [10].) The difference between the positive and the negative $\mathrm{CI}\left(\mathrm{O}_{2}\right)$ spectrum can be explained by the relative rates of the various processes: Formation of $\mathrm{M}^{+}$of 1 by charge exchange with $\mathrm{O}_{2}^{+'}$ is a fast process which is leading to abundant species (as with all aromatic compounds) and which competes well with the route comprising oxidation and subsequent ionization. In the negative mode (as mentioned above), formation of ions by ion-molecule reactions of 1 is a relatively slow process and hence the ions of the oxidation products dominate the spectrum.

The proposed oxidation of the sulfur atom of 1 to give 3 is confirmed by the $\mathrm{NCI}\left(\mathrm{O}_{2}\right)$ mass spectra of the oxygen and nitrogen analogs of 1 , dibenzofuran 5 and $9 \mathrm{H}$-carbazole 6 . They show $\left[\mathrm{M}+\mathrm{O}_{2}\right]^{-}$ions of low abundance only [9\% (5) and 17\% (6)], the dominating peaks being the ion-molecule-reaction products $m / z$ $183\left(\left[\mathrm{M}+\mathrm{O}-\mathrm{H}^{-}\right)(5)\right.$ and $m / z 166\left([\mathrm{M}-\mathrm{H}]^{-}\right)(6)$. Obviously the $-\mathrm{S}-$ group of 1 is as prone to oxidation to $-\mathrm{SO}_{2}-$ as the $-\mathrm{CH}_{2}-$ group of fluorene is

Table 1. Most important ions in the $\mathrm{NCI}\left(\mathrm{O}_{2}\right)$ spectrum of 1 and mass shifts observed for 2 and for 1 and 2 under $\mathrm{NCr}\left({ }^{18} \mathrm{O}_{2}\right)$ conditions

\begin{tabular}{|c|c|c|c|c|c|}
\hline $\begin{array}{c}m / z \\
1\end{array}$ & 2 & $\begin{array}{c}\text { Mass shift } \\
1\left({ }^{18} \mathrm{O}_{2}\right)\end{array}$ & $2\left({ }^{18} \mathrm{O}_{2}\right)$ & $\begin{array}{c}\text { Elemental } \\
\text { composition }\end{array}$ & Assignment \\
\hline 64 & +0 & +4 & +4 & $\mathrm{SO}_{2}$ & $\mathrm{SO}_{2}^{-}$ \\
\hline 73 & +1 & +6 & +7 & $\mathrm{C}_{2} \mathrm{HO}_{3}$ & $\mathrm{OHC}-\mathrm{COO}^{-}$ \\
\hline 80 & +0 & +6 & +6 & $\mathrm{SO}_{3}$ & $\mathrm{SO}_{3}^{-\prime \prime}$ \\
\hline 96 & +0 & +8 & +8 & $\mathrm{SO}_{4}$ & $\mathrm{SO}_{4}^{-}$ \\
\hline 113 & +1 & +8 & +9 & $\mathrm{C}_{4} \mathrm{HO}_{4}$ & $\mathrm{HOOC}-\mathrm{C} \equiv \mathrm{C}-\mathrm{COO}^{-}$ \\
\hline 152 & +4 & +4 & +8 & $\mathrm{C}_{7} \mathrm{H}_{4} \mathrm{SO}_{2}$ & $15^{-}$ \\
\hline 168 & +4 & +6 & +10 & $\mathrm{C}_{7} \mathrm{H}_{4} \mathrm{SO}_{3}$ & $13^{-}$ \\
\hline 184 & +4 & +8 & +12 & $\mathrm{C}_{7} \mathrm{H}_{4} \mathrm{SO}_{4}$ & $11^{-\cdot}$ \\
\hline 199 & +7 & +2 & 19 & $\mathrm{C}_{12} \mathrm{H}_{7} \mathrm{SO}$ & {$[\mathrm{M}+\mathbf{O}-\mathbf{H}]^{-}$} \\
\hline 200 & +8 & +2 & +10 & $\mathrm{C}_{12} \mathrm{H}_{8} \mathrm{SO}$ & {$[M+o]^{-\cdot}$} \\
\hline 214 & +6 & +4 & +10 & $\mathrm{C}_{12} \mathrm{H}_{6} \mathrm{SO}_{2}$ & {$[\mathrm{M}+2 \mathrm{O}-2 \mathrm{H}]^{-}$} \\
\hline 216 & +8 & +4 & +12 & $\mathrm{C}_{12} \mathrm{H}_{8} \mathrm{SO}_{2}$ & {$[M+20]^{-}$} \\
\hline 232 & +8 & +6 & +14 & $\mathrm{C}_{12} \mathrm{H}_{3} \mathrm{SO}_{3}$ & {$[\mathrm{M}+3 \mathrm{O}]^{-\cdot}$} \\
\hline 248 & +8 & +8 & +16 & $\mathrm{C}_{12} \mathrm{H}_{8} \mathrm{SO}_{4}$ & {$[M+40]^{--}$} \\
\hline $262 / 264$ & & & & see text & \\
\hline 280 & +8 & +8 & +16 & $\mathrm{C}_{12} \mathrm{H}_{8} \mathrm{~S}_{2} \mathrm{O}_{4}$ & {$\left[\mathrm{M}+\mathrm{SO}_{4}\right]^{-} ;\left[\mathrm{M}+2 \mathrm{O}+\mathrm{SO}_{2}\right]^{-}$} \\
\hline
\end{tabular}


to oxidation to $\mathrm{C}=\mathrm{O}[10]$. Also in accordance with an oxidation $1 \rightarrow 3$ are the $\mathrm{NCI}\left(\mathrm{O}_{2}\right)$ mass spectra of the dibenzothiophene sulfoxide 7 (Figure 4) and the sulfone 3 (Figure 5): They show, though with different abundances, all the ions also observed in the $\mathrm{NCI}\left(\mathrm{O}_{7}\right)$ mass spectrum of 1 with one important exception: In the case of $3, m / z 152$ is missing. The $\mathrm{NCI}\left(\mathrm{O}_{2}\right)$ spectrum of the sulfinate 4 (Figure 6) shows, including $m / z 152$, all the ions observed with 1 . These observations will be taken up below.

In the $\left.\mathrm{NCI}_{2} \mathrm{O}_{2}\right)$ mass spectra of the four isomeric methyldibenzothiophenes (8, Figure 7 , is given as an example), all the $\left[\mathrm{M}+\mathrm{O}_{\mathrm{n}}\right]^{-}$and $\left[\mathrm{M}+\mathrm{O}_{\mathrm{n}}-2 \mathrm{H}\right]$ ions are shifted by $14 \mathrm{u}(m / z) 214,230$, etc., and $m / z 228,244$, etc.), but the series $m / z$ 152, 168, 184 is accompanied by an homologous series $m / z$ $166,182,198$. Also, the $\mathrm{NCI}\left(\mathrm{O}_{2}\right)$ mass spectrum of 1,3 dimethyldibenzothiophene 9 shows two series, $m / z$ $152,168,184$ and $m / z 180,196,212$, whereas 2,8 dimethyldibenzothiophene 10 only shows one series, $m / z 166,182,198$.

The mass shifts upon introduction of methyl groups suggest that the ions of the series $m / z 152,168,184$ obtained with 1 are somehow related with the oxidation products. In addition, Figure 3 shows that they are shifted by $4 \mathrm{u}$ and hence can comprise only one of the benzene rings. Thus, $m / z 184$ cannot be $\mathrm{M}^{-}$; as suggested earlier $[2,3]$. This is in agreement with the calculated low electron affinity (EA) of 1 (EA $=-0.73$ [34] or $+0.08 \mathrm{eV}$ [35]) since stable molecular anions are to be expected only if $\mathrm{EA} \geq 0.5 \mathrm{eV}$ [36]. Exact mass measurements give an elemental composition of $\mathrm{C}_{7} \mathrm{H}_{4} \mathrm{SO}_{4}$ (the number of oxygen atoms is confirmed by the $\mathrm{NCI}\left({ }^{18} \mathrm{O}_{2}\right)$ mass spectrum of 1 , see Table 1$)$. This suggests that the ion $m / z \quad 184$ is actually 2sulfobenzoic acid cyclic anhydride (11) in analogy to phthalic anhydride obtained, for example, from fluorene via fluorenone under $\mathrm{NCI}\left(\mathrm{O}_{2} / \mathrm{N}_{2}\right)$ conditions $[7,37]$. The proposed structure of $m / z 184$ easily explains the homologous series observed with the methyldibenzothiophenes: 8 and its isomers yield $\mathbf{1 1}$ and a methyl substituted analog, 9 gives $\mathbf{1 1}$ and a dimethyl substituted analog, whereas the symmetrically substituted 10 gives a methyl substituted 11 only. The structure of $m / z 184$ is further confirmed by the

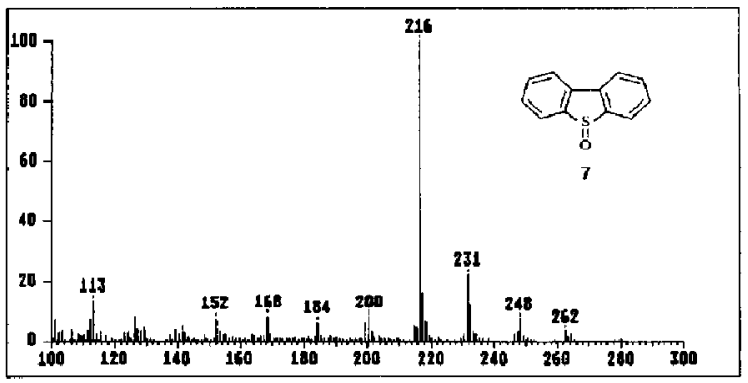

Figure 4. $\mathrm{NCI}\left(\mathrm{O}_{2}\right)$ mass spectrum of dibenzothiophene 5-oxide $7(\mathrm{M}=200)$.

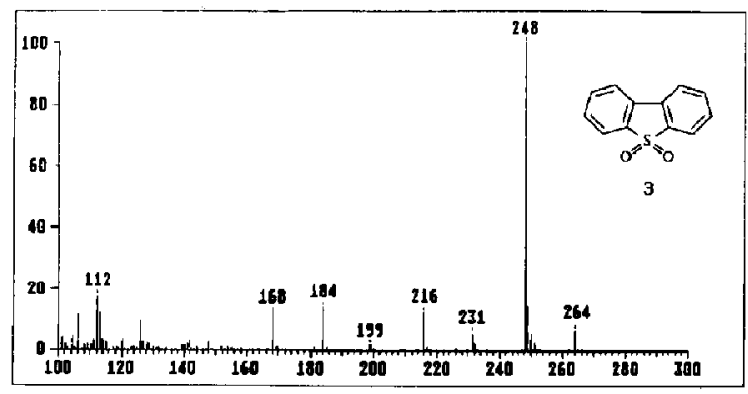

Figure 5. $\mathrm{NCI}\left(\mathrm{O}_{2}\right)$ mass spectrum of dibenzothiophene $5,5-$ dioxide $3(M=216)$.

identification of 2-sulfobenzoic acid as a $\mathrm{KMnO}_{4}$-oxidation product of 1: After treatment of the reaction mixture with $\mathrm{CH}_{2} \mathrm{~N}_{2}$, its dimethyl ester could be isolated and identified by comparison of the EI and ${ }^{1} \mathrm{H}$ - as well as ${ }^{13} \mathrm{C}$-NMR spectra with those of an authentic sample. 2-Sulfobenzoic acid has not been described previously as an cxidation product of 1 : By using other oxidizing reagents such as peracids, hydroperoxides, or $\mathrm{O}_{3}$, only 3 and/or 7 have been obtained [38-41].

Regarding the mechanism of oxidation leading to 11, it is suggested that 1 is first oxidized to 3 via 7 and subsequently the angular carbon atoms are attacked leading to 12. That only the angular carbon atoms are attacked is evident from the fact that 8 and all its isomers yield the same two series of characteristic ions discussed above. 12 by further reaction with oxygen is cleaved either to $11(m / z 184)$ or to $13(m / z$ 168) [formation of 13 by a fragmentation $11 \rightarrow 13$ is negligible as its intensities both in the $\mathrm{NCI}\left(\mathrm{CH}_{4}\right)$ and the $\mathrm{NCI}\left(\mathrm{O}_{2}\right)$ mass spectrum of 11 are $<2 \%$ of the base peak $\left(\mathbf{M}^{-}\right)$]. The ion $m / z 152$, as mentioned above, is not obtained from 3 (Figure 5), but rather from 7 (Figure 4). Its formation can be explained by a second analogous sequence of oxidation reactions starting from 7 leading to 14 which is oxidatively cleaved either to $13(m / z 168)$ or to $15(m / z 152)$. For 8 r oxidative cleavage can take place at either ring junction leading to the two series of homologous ions discussed before. As mentioned above the ions $m / z 152,168,184$ can also be found in the $\mathrm{NCI}\left(\mathrm{O}_{2}\right)$ mass spectrum of the

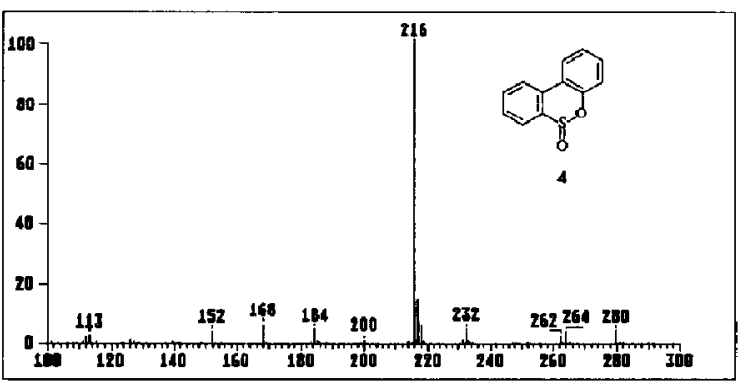

Figure 6. $\mathrm{NCI}\left(\mathrm{O}_{2}\right)$ mass spectrum of dibenz $[c, e l[1,2]$ oxathiin 6-oxide $4(M=216)$. 


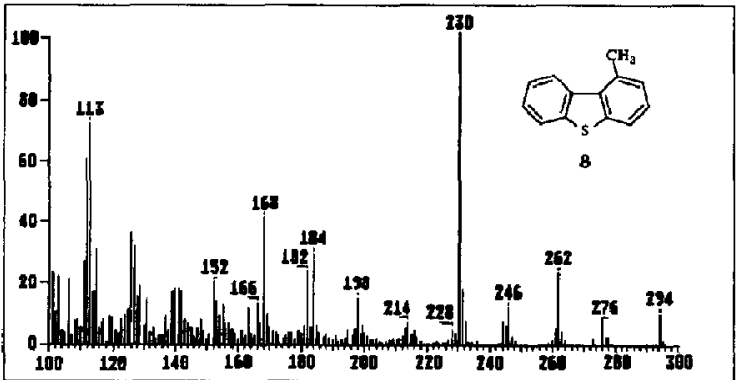

Figure 7. $\mathrm{NCI}\left(\mathrm{O}_{2}\right)$ mass spectrum of 1-methyldibenzothiophene $8(\mathrm{M}=198)$.

sulfinate 4 (Figure 6). They are not shifted upon introduction of a methyl group (sulfinate 16). This indicates (1) that their formation is initiated by an oxidative attack exclusively on the angular carbon atoms of the benzene ring attached to the $e$ bond of the oxathiin ring leading to 17, and (2) that a rearrangement $4 \rightarrow 3$ does not take place under $\mathrm{NCI}\left(\mathrm{O}_{2}\right)$ conditions. The back-rearrangement $3 \rightarrow 4$ can be excluded from the fact that $m / z 152$ is not observed with 3 . A thermal rearrangement $3 \rightarrow 4$ as mentioned above can be neglected under our experimental conditions since when subjected to GC mass spectrometry [the highest temperature being that of the $\mathrm{GC}$ injector $\left.\left(250^{\circ} \mathrm{C}\right)\right], 3$ as well as 4 gave only one peak each with different retention times. The crucial step in the proposed scheme is the oxidative ring opening $3 \rightarrow 12$. That this assumption is reasonable can be deduced from the fact that analogous ring cleavages have been described in the literature [42]. Scheme $I$ is the entire reaction ring. Species marked there with mass-to-charge ratio numbers are subsequently desorbed and transformed into negative ions by reaction with thermal electrons or charge exchange with plasma ions.

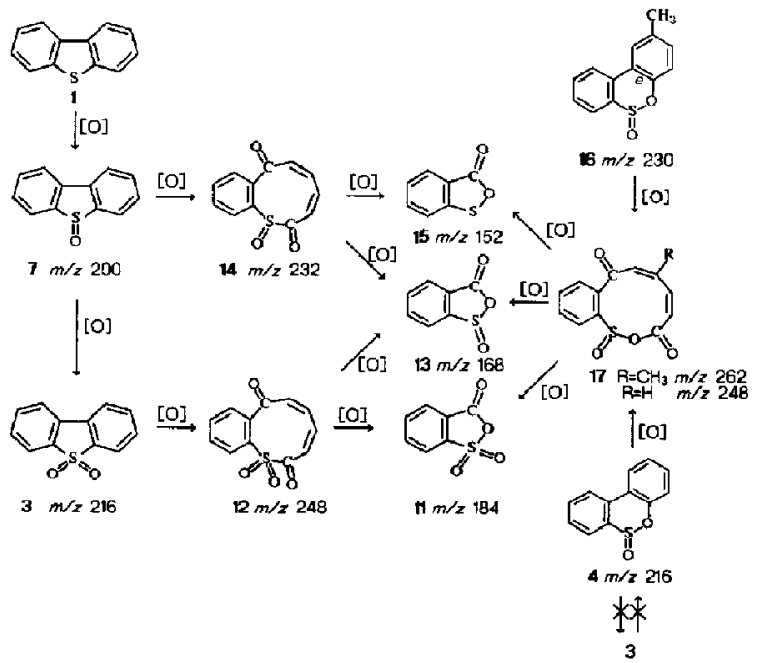

Scheme I. Oxidation reactions of dibenzothiophene 1 under $\mathrm{NCT}\left(\mathrm{O}_{2}\right)$ conditions.
Three ions in the $\mathrm{NCI}\left(\mathrm{O}_{2}\right)$ spectrum of 1 not fitting into Scheme I have to be mentioned shortly. The species $m / z 280$ contains only four O-atoms (see Table 1) and thus does not continue the series $\left[M+\mathrm{O}_{n}\right]^{-}$: It is shifted to $m / z 294$ for 8 and its isomers. It may either be an adduct ion $\left[\mathrm{M}+\mathrm{SO}_{4}\right]^{-}$or (as in polysulfuric acids) an adduct of $\mathrm{SO}_{2}$ to one of the oxygen atoms of 3. A likely structure could be:<smiles>c1ccc2c(c1)sc1ccccc12</smiles>

1<smiles>O=S1(=O)c2ccccc2-c2ccccc21</smiles><smiles>O=S1C2=C(c3ccccc32)c2ccccc21</smiles><smiles>Cc1ccc2sc3ccc(C)cc3c2c1</smiles>

10<smiles></smiles>

18<smiles>[2H]c1c([2H])c([2H])c2c(sc3c([2H])c([2H])c([2H])c([2H])c32)c1[2H]</smiles>

2<smiles>c1ccc2c(c1)oc1ccccc12</smiles>

5<smiles>Cc1cccc2sc3ccccc3c12</smiles>

8<smiles>O=C1OS(=O)(=O)c2ccccc21</smiles><smiles>O=S1(=O)c2ccccc2-c2ccccc21</smiles>

3<smiles>c1ccc2c(c1)[nH]c1ccccc12</smiles><smiles>Cc1cc(C)c2c(c1)sc1ccccc12</smiles>

9<smiles>Cc1ccc2c(c1)-c1ccccc1S(=O)(=O)O2</smiles>

The ions $m / z 262 / 264$ (shifted to $276 / 278$ for 8 and its isomers) can also be found in the spectra of 3,4 , and 7 . Here the shifts caused by ${ }^{2} \mathrm{H}$ and ${ }^{18} \mathrm{O}$ are puzzling: For 1 (Figure 2), $m / z 262$ is the most abundant species, but for 2 (Figure 3), $m / z 272$ is observed, which can only be the $d_{8}$-analog of $m / z$ 264. An explanation would be that $m / z 262$ belongs to the $\left[\mathrm{M}+\mathrm{O}_{\mathrm{n}}-2 \mathrm{H}\right]^{-} \cdot$ series and a loss of $\mathrm{D}_{2}$ is much less favorable than that of $\mathrm{H}_{2}$, and hence $m / z 270$ is essentially missing. The ${ }^{18} \mathrm{O}$ data show a shift to $\mathrm{m} / \mathrm{z}$ 270 for 1 and to $m / z 280$ for 2 , which requires an incorporation of four O-atoms $(262+8 \mathrm{u}$ and $272+8 \mathrm{u})$. No structures can be proposed for these ions. 


\section{Conclusions}

Due to its low electron affinity, dibenzothiophene 1 is a poor substrate for NCI when nonreactive reagent gases such as $\mathrm{CH}_{4}$ are used. However, when oxygen is used as a reagent gas, I suffers extensive surface-catalyzed oxidation by which species of high electron affinity are formed. They are readily ionized by electron capture and, therefore, dominate the $\mathrm{NCI}\left(\mathrm{O}_{2}\right)$ mass spectrum. The oxidation is initialized by formation of the sulfoxide 7 and especially the sulfone 3, which are further oxidized and degraded to the highly oxidized ions $\mathrm{C}_{7} \mathrm{H}_{4} \mathrm{SO}_{\mathrm{n}}(\mathrm{n}=2 \ldots 4)(\mathrm{m} / z 152,168,184)$. The ion $m / z 184$ is not $\mathrm{M}^{-}$but rather the anion of 2-sulfobenzoic acid cyclic anhydride. That an $\left[\mathrm{M}+\mathrm{O}_{2}\right]^{--}$ion not necessarily dominates the upper mass range of thiophene derivatives can be scen from the $\mathrm{NCT}\left(\mathrm{O}_{2}\right)$ spectrum of naphtho[2,3-b]thiophene (18), where the most important species is $m / z 214\left(\left[\mathrm{M}+\mathrm{O}_{2}-2 \mathrm{H}\right]^{-}\right)$, that is, formation of a quinone $[10,37], m / z 216$ amounting to only $20 \%$ of $\mathrm{m} / \mathrm{z} 214$. Hence, low abundance of $\left[\mathrm{M}+\mathrm{O}_{2}\right]^{-}$ions cannot be taken as a prima facie evidence against thiophenic compounds. In a following communication the $\mathrm{NCl}\left(\mathrm{O}_{2}\right)$ spectra of different types of thiophenic compounds will be reported and the structural prerequisites for the relative importance of the competing reactions will be discussed. In any case, some structural information can be obtained with $\mathrm{NCI}\left(\mathrm{O}_{2}\right)$ while EI or CI (positive and negative) with other reagent gases in most cases just gives the molecular mass.

\section{Acknowledgments}

Financial assistance by Deutsche Forschungsgemeinschaft (Bu 196-16) and Fonds der Chemischen Industrie (No. 486) is gratefully acknowledged.

\section{References}

1. Budzikiewicz, H.; Blech, St.; Schneider, B. Org. Mass Spectrom. 1991, 26, 1057-1060.

2. Hunt, D. F.; Stafford, Jr., G. C.; Crow, F. W.; Russell, J. W. Anal. Chem. 1976, 48, 2098-2105.

3. Hunt, D. F. Finnigan Spectra 1976, 6, 1-6.

4. Hunt, D. F.; Shabanowitz, J. Anal. Chem. 1982, 54, 574-578.

5. Hunt, D. F.; Brumely, W. C.; Stafford, G. C.; Botz, F. K. In Mass Spectrometry, part B; Merritt, Jr., C,; McEwen, C. N., Eds. Dekker: New York, 1980; pp 327 ff.

6. v. Ardenne, M.; Steinfelder, K.; Tümmler, R. Elektronenanlagerungs-Massenspektrographie organischer Substanzen; Springer: Berlin, 1971; p 333.

7. Albers, G.; Knof, H. Org. Mass Spectrom. 1977, 12, 698-702.

8. Tokarev, M. I.; Polyakova, A. A.; Kogan, L. O. J. Anat. Chem. USSR (Engl. Transl.) 1985، 40, 1347-1351.
9. Stemmler, E. A.; Hites, R. A. Biomed. Environ. Mass Spectrom. $1988,77,311-328$.

10. Stemmler, E. A.; Buchanan, M. V. Org. Muss Spectrom. 1989, $24,94-104$.

11. Harrison, A. G. Chemical Ionization Mass Spectrometry, 2nd ed., CRC: Boca Ratom, FI, 1992; pp $90 \mathrm{ff}$.

12. Schneider, B.; Breuer, M.; Hartmann, $H_{\text {.: }}$ Budzikiewicz, $H$. Org. Mass Spectrom. 1989, 24, 216-218.

13. Schneider, B.; Budzikiewicz, H. Org. Mass Spectrom. 1991, 26, 498-502.

14. Ashby, J.; Ayad, M.; Meth-Cohn, O. Chem. Connun. 1971, 1251.

15. Ashby, J.; Ayad, M.; Meth-Cohn, O. J. Chent. Soc., Perkin Trans. 1, 1974, 1744-1747.

16. Gourier, J.; Canonne, P. Bull. Soc. Chim. Fr. 1973, 3110-3115.

17. Neumoyer, C, R; Amstutz, E. D. J. Am. Chem. Soc. 1947, 69, 1920-1921.

18. Gilman, H.; Wilder, G. R. J. Org. Chem. 1957, 22, 523-526.

19. Goncalves, R.; Brown, E. V. J. Org. Chem. 1952, 17, 698-704.

20. Carruthers, W.; Douglas, A. G.; Hill, J. J. Chem. Soc. 1962, $704-708$.

21. Hanson, G.; Kemp, D. S. J. Org. Chem. 1981, 46, 5441-5443.

22. Jensen, S.; Löfgren, N. Acta Chem. Scand. 1968, 22, 2471-2475.

23. Gilman, H.; Esmay, D. L. I. Am. Chem. Soc. 1952, 74, 2021-2024.

24. de Boer, Th. J-; Backer, H. I. Recl. Trav. Chim. Pays-Bas 1954, $73,229-234$.

25. Oehme, M. Anal. Chem. 1983, 55, 2290-2295.

26. Hunt, D. F.; McEwen, C. N.; Harvey, T. M. Aral. Chem. 1975, $47,1730-1734$.

27. Mitchum, R. K.; Korfmacher, W. A.; Althaus, J. R. Org. Mass Spectram. 1984, 19, 63-66.

28. Harvey, T. M. Ph.D. Thesis, University of Virginia, 1975.

29. Hass, J. R.; Friesen, M. D.; Hoffman, M. K. Org. Mass Spectrom. 1979, 14, 9-16.

30. Hunt, D. F,; Sethi, S. K. ACS Sympositum Series 1978, 70, $150-178$.

31. Bowie, J. H.; Williams, D. H.; Lawesson, S.-O.; Madsen, J. Ø.; Nolde, C.; Schroll, G. Tetrahedron 1966, 22, 3515-3525.

32. Fields, E. K.; Meyerson, 5. J. Am. Chem. Suc. 1966, 88 , 2836-2837.

33. Budzikiewicz, H.; Djerassi, D.; Williams, D. H. Mass Spectrometry of Organic Compounds: Holden-Day: San Francisco, 1967; pp 556 ff.

34. Selsby, R. G.; Pennance, Ph.; Bamhard, K. I. Int. J. Quantum Chem. 1990, 37, 539-546.

35. Pal, S. K. Das Gupta, A.; Das Gupta, N. K. I. Indian Chem. Sac. 1990, 67, 134-139.

36. Buchanan, M. V.; Olerich, G. Org. Mass Spectrom. 1984, 19, 486-489.

37. Stemmler, E. A.; Buchanan, M. V. Org. Mass Spectrom. 1989, 24, 705-717.

38. Ashby, J.; Cook, C. C. Adv. Heterocycl. Chem. 1974, 16, 181-288.

39. LaCount, R. B.; Friedman, S. J. Org. Chetn. 1977, 42, 2751-2754.

40. Liotta, R.; Hoff, W. S. J. Org. Chem. 1980, 45, 2887-2890.

41. Dreher, W.j Klamberg, H. Fresenius' Z. Anal. Chem. 1988, 331, 290-294.

42. Friary, R. J.; Schwerdt, J. H. Tetrahedron 1991, 47, 9981-9984. 